\title{
Effect of Management and Topography on the Reproductive Performance of Azikheli Buffalo
}

\author{
Momen Khan', Muhammad Saleem¹, Farmanullah',a*, Mohammad Salim³, Saeed Ahmad ${ }^{4}$, \\ Hamayun Khan ${ }^{5}$, Ihsan Ullah Kakar ${ }^{2}$, Asma Babar², Bhunesh ${ }^{2}$, Sami Ullah Khan ${ }^{6}$, Inayat Ur \\ Rehman ${ }^{7}$, Seyed Mahdi Hosseini ${ }^{\mathrm{a}}$ \\ ${ }^{1}$ Livestock and Dairy Development, Khyber Pakhtunkhwa, Pakistan
}

${ }^{2}$ Faculty of Veterinary and Animal Sciences, Lasbela University of Agriculture, Water and Marine Sciences, Uthal, Pakistan

${ }^{3}$ Department of Forestry and Wildlife Management, the University of Haripur, Khyber Pakhtunkhwa, Pakistan

${ }^{4}$ Institute of Biological Sciences, Sarhad University of Science and Information Technology, Peshawar, Khyber Pakhtunkhwa, Pakistan

${ }^{5}$ Department of Animal Health, the University of Agriculture Peshawar-25120 Pakistan

${ }^{6}$ Laboratory of Microbiology and Immunology, College of Veterinary Medicine, Institute of Preventive Veterinary Medicine, Sichuan Agricultural University, Chengdu, China

${ }^{7}$ School of Marxism, China University of Geo Sciences (Wuhan), Hongshan District Region Wuhan, P.R.China

${ }^{a}$ Key Laboratory of Animal Genetics, Breeding and Reproduction, Ministry of Education, College of Animal Science and Technology, Huazhong Agricultural University, Wuhan, Hubei 430070, China

*Corresponding author: Dr. Farmanullah, Faculty of Veterinary and Animal Sciences, Lasbela University of Agriculture,

Water and Marine Sciences, Uthal, Balochistan,Email: farman_aup@yahoo.com; farman.vas@luawms.edu.pk

\section{ARTICLE INFO}

Received: 幽 July 21, 2020

Published: 崑 July 31, 2020

Citation: Momen K, Muhammad S, Farmanullah, Mohammad S, Saeed A, et al. Effect of Management and Topography on the Reproductive Performance of Azikheli Buffalo. Biomed J Sci \& Tech Res 29(2)2020. BJSTR. MS.ID.004770.

Keywords: Azikheli Buffalo; Reproductive Performance; Ecological Zones; Social Group; Indigenous Breed
ABSTRACT

The Azikheli buffalo is a native breed to the Hindukush Mountains of Northern Pakistan. It is kept in its home tract by different social groups (landowners, Gujars, and tenants) under different topographic conditions (hill slopes, undulating areas, and valley bottoms). The present study evaluated the management effect of social groups and topographic conditions on key reproductive traits. Such results are important to identify the likely habitat and management type that can host an indigenous breed conservation programme with success. Data was collected through a structured questionnaire from a total of 225 households representing the social groups and topographic zones aforementioned and was analyzed through a one-way analysis of variance. The results showed that social groups had no significant effect on the reproductive traits studied except for the postpartum anoestrus interval which was short $(\mathrm{P}<0.05)$ for the buffaloes reared by tenants than by landowners. Azikheli buffalo reaches puberty earlier at the valley bottom $(\mathrm{P}<0.01)$ than other zones and has a longer postpartum anoestrus interval at the hill slope $(\mathrm{P}<0.05)$ than the undulating zone. The better overall first service conception (62.69\%), number of services per conception $(1.53 \pm 0.06)$ and calving interval ( $480.62 \pm 7.30$ days) than other buffalo breeds under a variety of management conditions indicated a genotype-environment adaptability of the breed and warrants its conservation. Gujars with Azikheli herds and having a higher proportion of breeding bulls should be the primary recipients of a conservation programme.

\section{Introduction}

Indigenous livestock proves more efficient than 'improved' exotic breeds in ensuring financial returns [1,2]. This is all the truer in alow-input/low-output subsistence oriented farming system with limited access to markets [3]. Indigenous animal genetic resources reared in marginal ecological settings are therefore increasingly gaining attention $[4,5]$. The buffalo is spine of the farmer's economy of India, South-Asia, and a few European and American nations [6], profiting almost $50 \%$ of humankind in more than 40 nations [7],The buffalo is a significant domesticated animal's asset in a few nations of South Asia and the Mediterranean areas. The buffalo involves a significant spot among the domesticated creatures as a supplier of dairy produce, beef, and draft power. Notwithstanding, reproductive proficiency is undermined because of known issues 
of natural and board birthplaces, for example, absence of animal selections, and poor sustenance. The buffalo can use less quality roughages, adjust to harsher situations and are increasingly impervious to a few bovine-like tropical diseases. Their capacity to change over course feeds to milk and meat exceptional. In spite of these benefits, bison have moderately poor reproductive efficiency regardless of their area all through the world. Buffaloes displays a considerable lot of realized reproductive issues including postponed beginning of adolescence, poor oestrus articulation, longer baby blues, ovarian quiet, and above all brought down conception rates, especially when bred artificially [8]. In any case, higher fruitfulness could be accomplished through better taking care of and general administration $[9,10]$.

Numerous authors refer that the hereditary changeability of reproductive characteristics in buffalo is low $[11,12]$. In any case, most selections that have been proposed by Indian, Egyptian, and Pakistani scientists consistently consider reproductive examples $[13,14]$. Reproductive efficiency is one of the most significant variables for profitability and beneficially of dairy animals, and it has essential calculate the influencing efficiency of female buffalo, yet is enormously hampered by late accomplishment of puberty, seasonality of calving, long postpartum anoestrus and ensuing calving stretch. Late or postponed oestrus in buffalo calves is one of the major factors constraining its general productive and reproductive exhibition. The profitable and reproductive proficiency of animals are correlative to one another. Low reproductive proficiency as a rule and in buffalo specifically stays a significant financial issue, all inclusive. Ordinary reproductive tools to improve reproductive efficiency (fertility), intends to conquer reproductive imperatives, and cures are required. The reproductive efficiency in buffalo is so alarmingly low that it represents an intense danger of financial misfortune to Indian and animal husbandry experts [15]. In such a situation, an abundant scope exists for expanding the reproductive productivity by alterations in conventional techniques for rearing, breeding, taking care of, and management, and infection control.

Buffaloes have their idiosyncrasy with respect to the reproductive qualities, females are occasional polyestrous breeders of short days, the adolescence buffalo is reached at age more than in the bovine, the recognition of estrus is progressively troublesome as a result of the estrus it occurs at sunrise and the females of buffalo have barely any physiological changes makers experience issues distinguishing estrus. The gestation period differs somewhere in the range of 300 and 320 days. Males have smaller outside reproductive organs and less extraordinary sexual conduct comparable to cattle. Buffalo females show reproductive contrasts, for example, the hyper pigmented vulva and smaller and lighter, increasingly unbending and convolutedly internal structures with more muscle tone. There are a few favorable circumstances in the creation of buffaloes were proof, for example, their rusticity and adjustment to territories that would be unsuitable dairy cattle production, other than relying on items, for example, milk and meat of good quality. A few conventions of oestrus and ovulation synchronization have been embrace to improve reproductive effectiveness. These protocols have brought about a pregnancy rate increase of $30 \%$ to $50 \%$. It is reasoned that buffalo breeding includes space inside the animal production framework, particularly in territories that would be appropriate for the breeding of other ruminant species [16].

The Azikheli buffalo is an animal genetic resource of the Hindukush Mountain range known by farmers in the region for its reproductive performance [17]. This buffalo breed is kept by different social groups including Gujars, tenants, and landowners , each having different management objectives affecting the productive and reproductive performances of the breed [18]. The management differences among social groups are also affected by the topography through the variety of feed resources available during different seasons of the year [19]. Various factors affected on the reproductive performance of the Azikheli buffaloes. The detail physiological status and different lactations of Azikheli buffaloes in hill slope, undulating and plain ecological zones in Khwazakhela valley of District Swat, Khyber pakhtunkhawa have been reported in the previous paper. The reproductive performance of Azikheli Buffaloes calved in spring, summer, autumn, and winter seasons, and in hill slope, undulating and plain ecological zones of Khwazakhela valley of District Swat, Khyber pakhtunkhawa has been published in our previous manuscript [20].

To date, the extent to which management by social groups and topographic variability affect reproductive performance has not been evaluated [21]. This paper aims at filling this gap and intends to evaluate the effect of (1) social groups and (2) topographic zones on key reproductive traits of the Azikheli buffalo to provide an insight into the possible areas of intervention to conserve and improve this valuable animal genetic resource.

The household water buffalo (Bubalus bubalis) has a significant role in the agrarian economy of many developing nations in Asia, providing milk, meat, and draft power. It is additionally utilized in some Mediterranean and Latin American nations as a wellspring of milk and meat for specific markets. Buffaloes are fit for breeding consistently, yet in numerous nations a seasonal example of ovarian movement happens. This is credited in tropical areas to changes in precipitation bringing about feed accessibility or to temperature stress bringing about raised prolactin emission, and in temperature regions to changes in photoperiod and melatonin secretion. Information on genuine and ideal profitability levels and reproductive disorder rate for buffaloes kept up in provincial zones in a significant essential for understanding generally overall husbandry conditions and managing, guiding, planning, research, arranging, and extension endeavors in any territory. This information is additionally vital for building up focuses on execution for singular animals in rustic zones and choosing techniques for development and improvement of buffaloes [22]. 


\section{Materials and Methods}

\section{Home Tract, Study Area and Socio-Ecological Attributes}

The Azikhellibuffalo is rearedin bothsedentary and transhumant conditions. Its broader home tract includes the watersheds of the Swat River, the Panjkora River, and small tributary streams of the Indus River in (Figure 1). While the Azikheli buffalo breed is shown in (Figure 2). The study was conducted in three different ecological zones of Khwazakhela, namely, hill slopes , undulating areas , and valley bottoms by Gujars, landowners and tenants having different accesses to land, feed resources and livestock-rearing objectives. The attributes of the social groups are given in Table 1. In winter, animals are fed intensively for two to four months based on the provisions of the ecological zone. Buffaloes on hill slopes are fed with hay followed by maize stalks and tree leaves and with grazing in summer. In the undulating zones, they are fed with wheat straw followed by maize stalks and hay grazing in summer, and stubbles in autumn. In the valley bottoms, wheat straw, rice straw, and crop residues are provided with some partial riparian grazing throughout the year and stubbles during spring and autumn. Stall feeding is practiced by landowners while grazing is the main source of feeding from Gujars. Tenants feed their animals for partial stall feeding and grazing. Gujars are compelled to provide more concentrate during the first four months of lactation in comparison to tenant and landowner because of their dependency on milk sales.

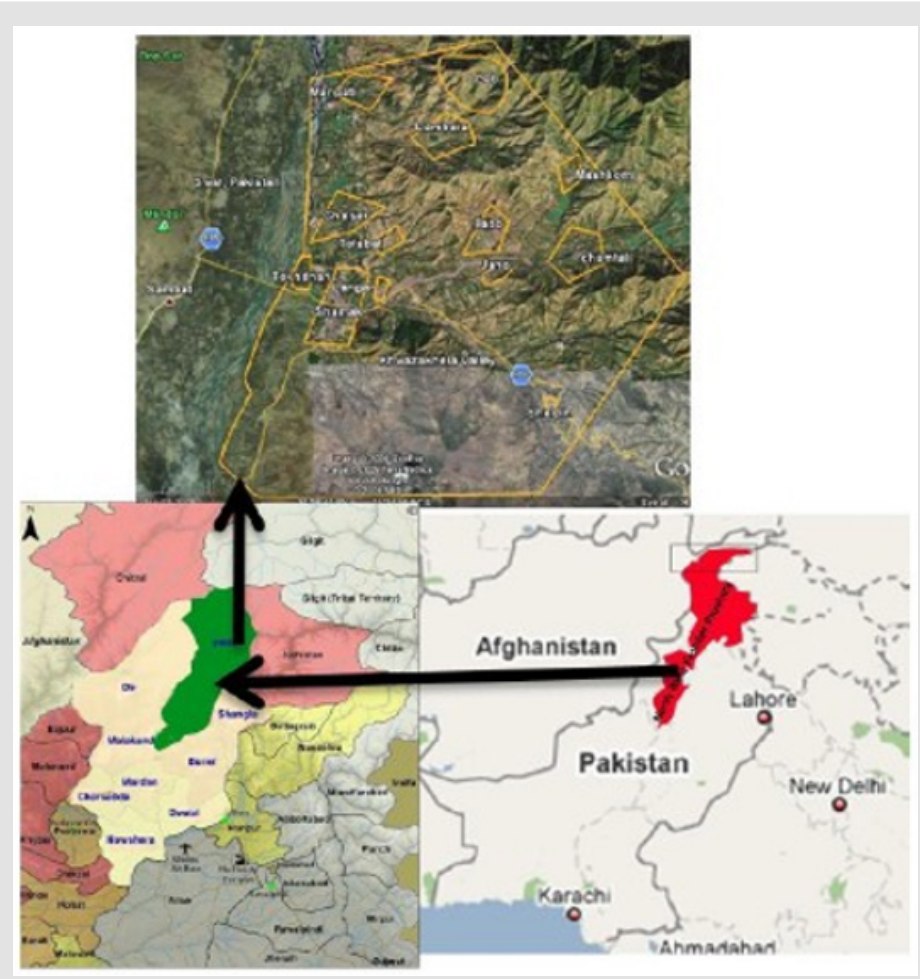

Figure 1: Map of the study area and Azikheli buffalo home tract.

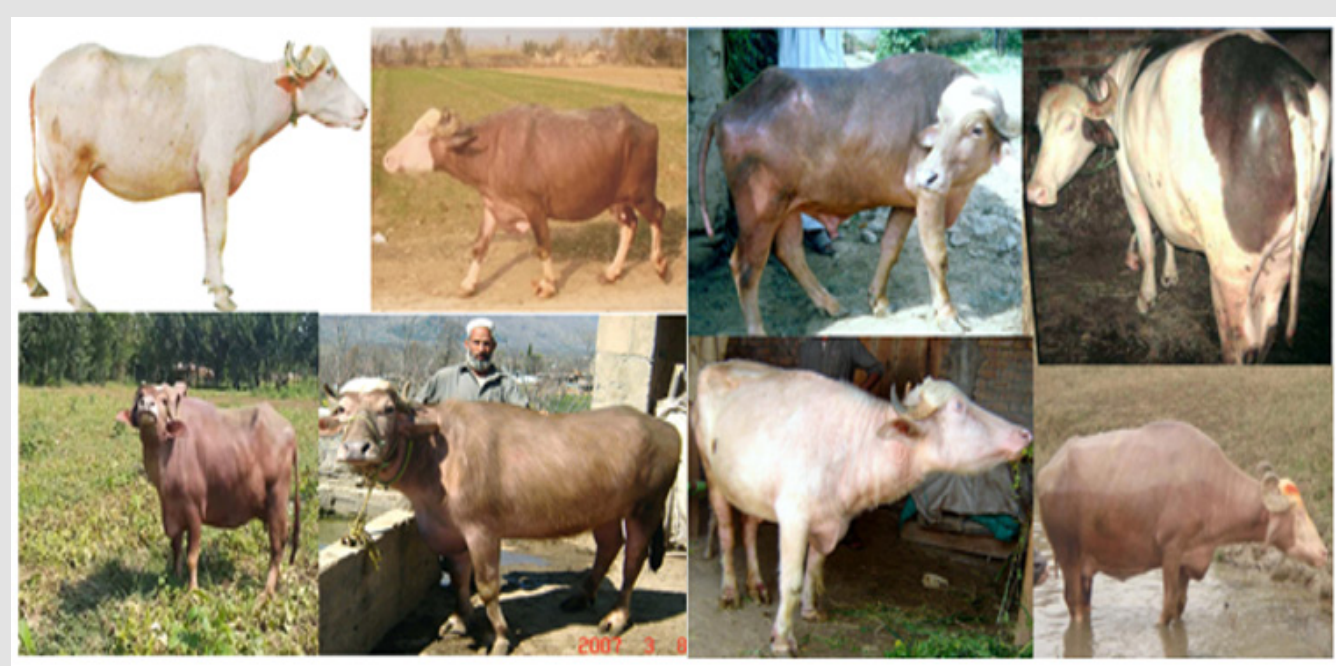

Figure 2: Azikheli Buffalo breed of different ages and sex at various locations of Khwazakhela Swat. [20,23]. 
Table 1: Livestock species' distribution by social groups.

\begin{tabular}{|c|c|c|c|}
\hline Variables & Landowners & Gujars & Tenants \\
\hline Average number of buffaloes per herd & $3.12 \pm 0.19$ & $5.42 \pm 0.30$ & $2.80 \pm 0.15$ \\
\hline Average proportion of Azikheli in herd (\%) & $80 \%$ & $85 \%$ & $73 \%$ \\
\hline Use of own bull for breeding (\%) & $7 \%$ & $16 \%$ & $6 \%$ \\
\hline Daily average milk $8.18 \pm 0.17$ liters (range: $4.24-13.66$ ) & $7.50 \%$ & $7.15 \%$ & $6.50 \%$ \\
\hline Primary dependency on livestock (\%) & $20 \%$ & $100 \%$ & $50 \%$ \\
\hline
\end{tabular}

\section{Sampling Pattern and Statistical Analysis}

A total of 225 households were randomly interviewed (25 households of each social group in each ecological zone). Data on pubertal age, postpartum anoestrus interval, first service conception rate, number of services per conception, and calving interval were collected by means of a structured questionnaire. First, service conception rate and number of services per conception was calculated according to $[23,24]$. A one-way analysis of variance with Tukey's multiple comparison post hoc test was used to analyze the effect of social groups and ecological zones on the above dependent variables.

\section{Results}

Ecological zones significantly affect the pubertal age by postponing the maturity of buffaloes reared on hill slopes when compared to those in undulating areas $(\mathrm{P}<0.05)$ and valley bottoms $(\mathrm{P}<0.05)$ (Table 2). However, the difference is not significant $(\mathrm{P}>0.05)$ between undulating zones and valley bottoms. Postpartum anoestrus interval was affected by both the social group and ecological zone. Shorter postpartum anoestrus interval was recorded in buffaloes reared by tenants $(\mathrm{P}<0.05)$ compared to landowners. The difference in postpartum anoestrus interval of buffaloes reared by landowners and Gujars $(\mathrm{P}>0.05)$ and Gujars and tenants $(\mathrm{P}>0.05)$ was statistically not significant. Azikheli buffaloes have significantly $(\mathrm{P}<0.05)$ shorter postpartum anoestrus intervals at undulating zones than at hill slopes. However, the difference between hill slopes and valley bottoms $(\mathrm{P}>0.05)$ and undulating zones and valley bottoms $(\mathrm{P}>0.05)$ was statistically not significant.

Table 2: Reproductive performance with different social group at different ecological.

\begin{tabular}{|c|c|c|c|c|c|}
\hline & PA (days) ${ }^{a}$ & PPAI (days) & FSCR (\%) & NSC & CI (days) \\
\hline \multicolumn{6}{|l|}{ Social group } \\
\hline Landowner & $1062.0 \pm 30.28$ & $164.39 \pm 14.35^{\mathrm{a}}$ & 57.97 & $1.68 \pm 0.13$ & $498.45 \pm 14.45$ \\
\hline Gujar & $1092.8 \pm 22.80$ & $128.03 \pm 13.93^{\mathrm{ab}}$ & 62.32 & $1.54 \pm 0.10$ & $468.72 \pm 13.45$ \\
\hline Tenant & $1087.6 \pm 24.07$ & $120.90 \pm 10.7^{b *}$ & 68.25 & $1.35 \pm 0.06$ & $475.22 \pm 8.72$ \\
\hline \multicolumn{6}{|l|}{ Ecological zones } \\
\hline Hill slope & $1164.4 \pm 24.59^{\mathrm{a}}$ & $159.74 \pm 14.81^{\mathrm{a}}$ & 67.69 & $1.51 \pm 0.11$ & $504.93 \pm 15.87$ \\
\hline Undulating & $1066.4 \pm 27.04 \mathrm{~b}^{* *}$ & $112.71 \pm 10.17^{\mathrm{b} *}$ & 52.17 & $1.65 \pm 0.11$ & $460.43 \pm 8.95$ \\
\hline Valley bottom & $1011.6 \pm 22.93 \mathrm{~b}^{* *}$ & $141.06 \pm 13.94^{\mathrm{ab}}$ & 68.65 & $1.42 \pm 0.09$ & $478.44 \pm 12.17$ \\
\hline
\end{tabular}

Note: ${ }^{\circledR P A}$ Puberty age; PPAI: Postpartum Anoestrus Interval; FSCR: First Service Conception Rate; NSC, Number of Services per Conception; CI, Calving Interval.

${ }^{\mathrm{a}, \mathrm{b}}$ Figures with different superscripts in the same column differ significantly ${ }^{*} \mathrm{p}<0.05 ;{ }^{* *} \mathrm{p}<0.01$.

\section{Discussion}

From hill slopes, the late attainment of puberty age compared to undulating zones $(\mathrm{P}<0.01)$ and valley bottoms $(\mathrm{P}<0.01)$ may be due to maize stalks based poor feeding [25,26]. [27] Reported that maize stalks feeding can delay the onset of puberty in buffaloes. Poor feeding at hill slopes compared to undulating zones $(\mathrm{P}<0.05)$ also seems to be a cause of longer postpartum anoestrus interval in Azikheli buffalo as reported by [28]. The lack of any significant difference for the postpartum anoestrus interval at hill slopes in comparison to valley bottom is unclear despite better feeding at the valley bottoms. Irrational use of concentrate feed with a higher intake of protein diet at valley bottoms may be a contributing factor to this non-significance, which has been reported to be adversely affecting fertility $[29,30]$. The significantly $(\mathrm{P}<0.05)$ short postpartum anoestrus interval for Azikheli buffaloes reared by tenants when compared to those reared by landowners may be due to a comparatively lower milk yield with tenants than with landowners. Higher milk yield has been reported to prolong the postpartum anoestrus interval [31,32].

The first service conception rate $(62.69 \%)$ of the Azikheli buffalo is higher than the $50 \%$ recommended value for buffaloes [33]. Moreover the mean number of services per conception of Azikheli buffalo $(1.53 \pm 0.06)$ can be considered satisfactory as 1.5 services per conception are reported to be satisfactory for a wellmanaged buffalo herd $[33,34]$. There was no significant effect of social group and ecological zones on first service conception rate, 
number of services per conception, and calving interval, indicating a genotype-environment adaptability of the breed [13]. The Comparison of reproductive performance of Azikheli with Nili-Ravi buffalo breeds such as the Azikheli buffalo cows generally has better reproductive performance than Nili-ravi except for puberty age which is shorter for Nili-ravi, as Azikheli Pubertal age (days) was

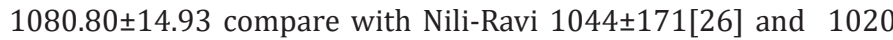
[35]. The Post-partum anoestrus interval (days) was 138.09 \pm 7.69 for Azikheli while it was reported in Nili-ravi 176.73 \pm 271 [36] and $183.42 \pm 2.37$ by [37]. The 1st service conception rate was $62.69 \%$ for Azikheli while at Nili-ravi it was reported $53.4 \%$ [38]. The number of services per conception was $1.53 \pm 0.06$ in Azikheli, it was reported in Nili-Ravi $1.7 \pm 0.12$ [39], and $1.7 \pm 0.7$ [39]. The Calving interval (days) was $480.62 \pm 7.30$ for Azikheli, it was reported 517.29 [33], and $508.06 \pm 2.76$ [40].

Different reasons have been given for late pubertal age in the literatures including genetic factors [41], feed scarcity and/or unavailability of balanced feed $[6,26]$, and poor management [4143]. However, our results suggest that for the Azikheli buffalo it is the feeding that significantly affects pubertal age. The overall mean calving interval observed in Azikheli buffalo (480.62 \pm 7.30 days) is better than for the Nili-Ravi buffalo breed but still below the ideal calving interval of 360 to 420 days [44].

\section{Conclusion}

The Azikheli buffalo is kept in its home tract by different social groups (landowners, Gujars, and tenants) under different topographic conditions (hill slopes, undulating areas, and valley bottoms). The present study evaluated the management effect of social groups and topographic conditions on key reproductive traits. A total of 225 households data was collected representing the social groups and topographic zones aforementioned and was analyzed. The results showed that social groups had no significant effect on the reproductive traits studied except for the postpartum anoestrus interval which was short $(\mathrm{P}<0.05)$ for the buffaloes reared by tenants than by landowners. Conservation of the Azikheli buffalo breed can be carried out with all social groups and at all topographic zones. However, Gujars are the primary herders with whom conservation can be pursued in the study area because of their large herd size with the higher possibility for selection and ability to afford a breeding bull. They are currently caring more for the breed as they are primarily dependant for their livelihood on the sale of livestock and livestock products.

The earlier puberty age at the valley bottom and undulating zone and a short postpartum anoestrus interval at the undulating zone provide scope for improvement through genetic selection and better feeding in other ecological zones also. The higher first service conception rate and less number of services per conception in comparison to other buffalo breeds irrespective of the social groups and ecological zones suggest it to be a specific genotype trait of Azikheli buffaloes and indicate good adaptability of the
Azikheli buffaloes to different ecological zones in the study area. The comparatively better reproductive performance of the Azikheli buffalo makes the Azikheli an important genetic resource in mountain environments and therefore warrants conservation of its key reproductive traits through appropriate breeding programs.

\section{Conflict of Interest}

All authors do not have any potential conflict of interest related to this research work.

\section{Acknowledgement}

The authors are thankful to anonymous reviewers for their valuable comments, suggestions, and critical reading of the manuscript. I am also very appreciative to the co-authors for their critical and technical improvement of our manuscript.

\section{Data Availability}

The data used to support the findings of this study are included within the article.

\section{References}

1. Anderson S (2003) Animal genetic resources and sustainable livelihoods. Ecological economics 45(3): 331-339.

2. Scarpa R, Adam Drucker, Simon Anderson, Nancy Ferraes Ehuan, Veronica Gomez, et al. (2001) Valuing animal genetic resources in peasant economies: the case of the Box Keken creole pig in Yucatan. SSRN Electronic Journal.

3. Scherf B, B Rischkowsky, I Hoffmann (2005) Status of animal genetic resources: time for action? in International Workshop. Options and Strategies for the Conservation of Farm Animal Genetic Resources.

4. Wagner H G R, K Hammond (1999) The Management of Farm Animal Genetic Resources and FAO's Global Strategy. Humboldt University.

5. Köhler Rollefson, I HS Rathore, E Mathias (2009) Local breeds, livelihoods and livestock keepers' rights in South Asia. Tropical animal health and production 41(7): 1061-1070.

6. Ingawale M, R Dhoble (2004) Buffalo reproduction in India: an overview. Buffalo Bull 23(1): 4-9.

7. Bandyopadhyay A, P Ray, P Ghatak (2003) Effective utilization of buffalo milk for manufacturing dairy products. Asian buffalo congress.

8. Warriach H, D M Mc Gill, R D Bush, P C Wynn, K R Chohan (2015) A review of recent developments in buffalo reproduction-a review. AsianAustralasian journal of animal sciences 28(3): 451-455.

9. Qureshi M, S Khan, N Ahmad (2007) Pregnancy depresses milk yield in dairy buffaloes. Italian Journal of Animal Science 6(sup2): 1290-1293.

10. Amini Jabalkandi, J G Manafiazar, S Razzagzadeh (2007) Effect of supplemented ration on some reproductive traits in Azeri buffaloes of Iran. Italian Journal of Animal Science 6(sup2): 1284-1286.

11. Raheja K (1992) selection free estimates of genetic parameters of production and reproduction traits of 1 st 3 lactations in murrah buffalos. Indian journal of animal sciences 62(2): 149-154.

12. Tomar S (1992) Estimates of heritability of utero-vaginal disorders in a herd of Murrah buffalo. Ind J Anim Sci 62: 663-664.

13. Catillo G, B Moioli, F Napolitano (2001) Estimation of genetic parameters of some productive and reproductive traits in italian buffalo. Genetic evaluation with blup animal model. Asian-Australasian Journal of Animal Sciences 14(6): 747-753. 
14. Juma K, GA Baghdasar, S Said (1991) Iraqi buffaloes v: calving interval and breeding efficiency.

15. Ramesh V, T V Thanga A. Varadharajan (2002) Improvement of reproductive performance of buffaloes.

16. Pirondi A N, Cynthia Maria, Erico da Silva, Tiago Neves, Fernanda de Campos, et al. (2019) Reproductive Characteristics of Buffaloes: A Review. Journal of Agricultural Science 11(13).

17. Shah S I, Inam Rahim, Henri Rueff, Daniel Maselli (2012) Landless mobile pastoralists: Securing their role as custodians of northern Pakistan's mountains. Centre for Development and Environment (CDE).

18. Viaro M A (2002) Swat: An Afghan society in Pakistan: Urbanisation and Change in a Tribal Environment. Institut universitaire d'études du développement.

19. Berkes F, D Jolly (2002) Adapting to climate change: social-ecological resilience in a Canadian western Arctic community. Conservation ecology 5(2).

20. Khan M, Muhammad Saleem, Inam Rahim, Hamayun Khan, Ali Gohar, et al. (2014) Assessment of morphometric, productive and reproductive characteristics of Azikheli Buffalo in Swat valley in Northern Pakistan. Life Sci J 11(12): 1-8.

21. Rasali D (2000) Recent trends in buffalo production in Nepal-A review. Buffalo Newsletter 14: 6-10.

22. Prasad S, R Prasad (1998) Measures of reproductive estimates in rura buffalo herds of Meerut district of Uttar Pradesh (India) Buffalo Bull 17(2): 27-29.

23. Khan M, I Rahim, H Rueff, S Jalali, M Saleem, et al. (2013) Morphological characterization of the Azikheli buffalo in Pakistan. Animal Genetic Resources/Resources 52: 65-70.

24. Fetrow J, David Mc Clary, Robert Harman, Ken Butcher, Leon Weaver, et al. Calculating selected reproductive indices: recommendations of the American Association of Bovine Practitioners. Journal of Dairy Science 73(1): 78-90.

25. Akhtar T, Rashad M A, Lodhi LA, Khanum S A, Hussain M (2007) Improving reproductive efficiency in an artificial insemination programme through early non-pregnancy diagnosis, management and training. Reproductive Management of Dairy Cattle Subjected to Artificial Insemination 103.

26. Rafiq M, M Chaudhry, M Jabbar (2008) Effect of level of concentrate supplementation on growth rate and age at maturity in growing buffalo heifers. Pakistan Veterinary Journal 28(1): 37-39.

27. Rekwot P (2004) Effects of feeding maize stover and cottonseed cake on onset of puberty in Bunaji (Bos indicus) heifers. Tropical animal health and production 36(7): 637-644.

28. Montiel F, C Ahuja (2005) Body condition and suckling as factors influencing the duration of postpartum anestrus in cattle: a review. Animal Reproduction Science 85(1-2): 1-26.
29. Ferguson JD, David T Galligan, Terry Blanchard, Matthew Reeves (1993) Serum urea nitrogen and conception rate: the usefulness of test information. Journal of dairy science 76(12): 3742-3746.

30. Qureshi MS, Ghulam Habib, Hafiz Abdus Samad, Muhammad Mohsin Siddiqui, Nazir Ahmad, et al. (2002) Reproduction nutrition relationship in dairy buffaloes. I. Effect of intake of protein, energy and blood metabolites levels. Asian-australasian journal of animal sciences 15(3): 330-339.

31. Singh N, F Chauhan, M Singh (1979) Postpartum ovarian activity and fertility in buffaloes. Indian journal of dairy science.

32. Opsomer G, Y T Gröhn, J Hertl, M Coryn, H Deluyker, et al. (2000) Risk factors for post partum ovarian dysfunction in high producing dairy cows in Belgium: a field study. Theriogenology 53(4): 841-857.

33. Shah S N H, A H Willemse, D F M Van De Wiel, B Engel (1989) Influence of season and parity on several reproductive parameters in Nili-Ravi buffaloes in Pakistan. Animal Reproduction Science 21(3-4): 177-190.

34. Mohamed A A, A El Sheikh (1983) Post-partum ovulation in a herd of Egyptian buffaloes. Indian Journal of Animal Sciences (India).

35. Rehman S, M Ahmad, M Shafiq (2006) Comparative performance of Sahiwal cows at the Livestock Experiment Station, Bahadurnagar, Okara vs patadar's herd. Pakistan Veterinary Journal 26(4): 179.

36. Hussain J, Muhammad Aftab Khan, Ghulam Mohiuddin, Bakht B Khan, Muhammad Shafique (1993) Repeatability Estimates Of Some Reproductive Traits In Nili-Ra Vi Buffaloes. Pak J Agri Sci 30(4).

37. Rehman A (1989) Studies on nili-ravi buffaloes in Pakistan 1. Effect of environmental factors on some reproductive traits. Sarhad Journal of Agriculture (Pakistan).

38. Usmani R, M Mirza (2000) Influence of parity and month of peak calving season on postpartum estrous activity and fertility of Nili-Ravi buffaloes Pakistan Journal of Biological Sciences 3(12): 2179-2181.

39. Usmani R, N Ahmad, P Shafiq M A Mirza (2001) Effect of subclinical uterine infection on cervical and uterine involution, estrous activity and fertility in postpartum buffaloes. Theriogenology 55(2): 563-571.

40. Chaudhry M A, M H Chohan, T N Pasha (1990) Uterine Involution And Postpartum Oestrus In Primiiparous Niili-Ravi Buffaloes. Pakistan J Agric Res Vol 11(3): 183-191.

41. Perera B (2011) Reproductive cycles of buffalo. Animal reproduction science 124(3-4): 194-199.

42. Barkawi A, E Mokhless, L Bedeir (1989) Environmental factors affecting age at puberty in Egyptian buffaloes. Buffalo J 1: 71-78.

43. Hogberg M, O Lind (2003) Milk Production of Buffalo. Buffalo Milk Production.

44. Yadav B (2007) Study of economic traits in Murrah buffaloes. Buffalo Bull 26(1): 10-14.

ISSN: 2574-1241

DOI: 10.26717/BJSTR.2020.29.004770

Farmanullah. Biomed J Sci \& Tech Res

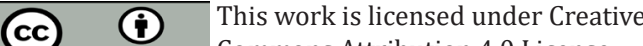

Commons Attribution 4.0 License

Submission Link: https://biomedres.us/submit-manuscript.php

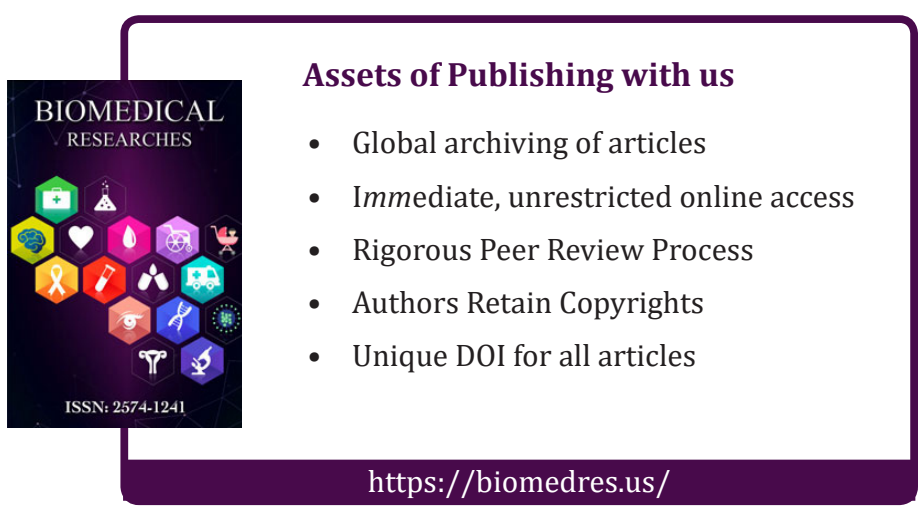

Copyright@ Farmanullah | Biomed J Sci \& Tech Res | BJSTR. MS.ID.004770. 